\title{
Relationship between Adequate Healthcare Facilities and Population Distribution in Melaka Using Spatial Statistics
}

\author{
Rosilawati Zainol ${ }^{1}$ and Hanan Elsawahli ${ }^{2}$ \\ ${ }^{1}$ Centre for Sustainable Urban Planning and Real Estate (SUPRE), Faculty of Built \\ Environment, University of Malaya, Malaysia \\ ${ }^{1}$ Centre for Civilizational Dialogue, Humanities Research Cluster, University of Malaya, \\ Malaysia \\ ${ }^{2}$ Faculty of Architecture, The National Ribat University, Sudan
}

*rosilawatizai@um.edu.my

Received : 09 August 2017 Final Version Received: 28 February 2018

\begin{abstract}
Healthcare facilities are required for all levels of a population regardless of age, race or socioeconomic status. Provision for healthcare facilities requires knowledge of population data and area for placement of healthcare facilities. The main objective of this paper is to examine the relationship between availabilities of healthcare facilities and population in districts in Melaka. This study is based on population data and distribution of healthcare facilities which were obtained from the Department of Statistics Malaysia and Malaysia Administrative Modernisation and Management Planning Unit (MAMPU). Both types of data were converted into geographic information systems (GIS) data format using QuantumGIS. Then these data were analysed using two main methods using GeoDa and ArcGIS applications. First is by using a formula set by a global standard, ISO37120 to measure healthcare facilities adequacy. Secondly, spatial statistics, Bivariate Moran's I was used to examine the relationship between population and healthcare facilities distribution. Local Moran's I was used to examine the cluster of population distribution. Findings show the allocation of healthcare facilities is sufficient according to the Malaysian Community Facilities Guideline. A high-high cluster of the population is found in Melaka Tengah District. However, the relationship between the total population and number of public hospital in-patient beds are negatively correlated. Similar results are obtained for private clinics and pharmacy. This result shows higher population distribution has less number of public hospital inpatient beds, the number of private clinics and pharmacy. However, Bivariate Moran's I analysis yields a different output for the public clinic. This result shows the high number of population distribution is positively correlated with a high number of public clinics. Thus, authorities, in this case, would be the Ministry of Health and Melaka state government should be aware of the current availability of healthcare facilities to its population in ensuring a high level of healthcare services provided in the state.
\end{abstract}

Keywords: Healthcare Facilities, Population Distribution, Bivariate Moran's I, QuantumGIS, GeoDa, Local Moran's I, Melaka

\section{INTRODUCTION}

Healthcare facilities are required for all levels of population. Adequate healthcare facilities contribute to better population health (Gulliford, Jack, Adams, \& Ukoumunne, 2004). Availability of healthcare facilities is often being debated. Total number of beds and doctors at medical institutions for example, are considered as essential parameters in providing facilities to the general public (Chakraborty \& Sen, 2011). Most developing countries face difficulties in providing these facilities. Nigeria, for example, faced issues of better equity in accessing healthcare facilities and quality of services (Oyekale, 2017). Although the number of healthcare facilities may be equally distributed among the local government areas, it may not yield the true indicator. Sometimes the location of health facilities plays a big role in creating higher accessibility to the local community. Difficulties in accessing the facilities by the rural communities, rapid population growth and lack of proper attention to patients may not reflect adequate supply of healthcare facilities (Ujoh \& Kwaghsende, 2014). Countries in Europe are creating larger and more specialised healthcare facilities to achieve economies of scale. However, findings by Pantzartzis, Edum-Fotwe and Price (2017) show small facilities can be more viable. Thus, fitting mitigation, adaptation strategies and resilience practices in meeting specific needs would be the best approaches to be considered (Ilesanmi \& Mgbemena, 2015). 
This study intends to examine the relationship between availabilities of healthcare facilities and population in districts in Melaka. In this study, healthcare facilities refer to hospitals, clinics and pharmacies.

\section{ADEQUATE OR ACCESSIBLE HEALTHCARE FACILITIES}

Many methods have been used to determine the allocation of healthcare facilities. Among others include, integrated accessibility and locationallocation models (Polo, Acosta, Ferreira, \& Dias, 2015), framework for emergency and non-emergency healthcare facilities (AhmadiJavid, Seyedi, \& S.Syam, 2017), probability metric to social programs (Radke \& Mu, 2000), a two-step floating catchment area method based on geographic information system (GIS) (Kanuganti, Sarkar, \& Singh, 2016; Song, Zhu, Mao, Li, \& An, 2013), three-step floating catchment area (Wan, Zou, \& Sternberg, 2012), multi-modal two step floating catchment area analysis (Langford, Higgs, \& Fry, 2016) and a cumulative case ratio (Zinszer et al., 2014). Some scholars review the methods used. Rahman and Smith (2000) review the use of location-allocation model. Daskin and Dean (2004) on the other hand, review the location set covering model, maximal covering model and P-median model. Most of these researches focus on accessibility. Thus, proximity to healthcare facilities and demand for healthcare services seem to be the main criteria in selecting the best location.

\section{STANDARD AND GUIDELINE OF HEALTHCARE FACILITIES}

According to ISO37120 (2014), the number of in patient public hospital beds (core indicator) can be used as one of the indicators to monitor the level of health service delivery. This score is calculated by dividing the number of inpatient hospital beds and the total number of population which is later multiplied by 100000 (ISO, 2014). Different countries have different guidelines in providing healthcare facilities. In Malaysia, healthcare facilities provision is guided by a special guideline known as Community Facilities Guideline (Jabatan Perancangan Bandar dan Desa Semenanjung Malaysia, 2013). It is designed to assist state authority, local authority, implementing agencies and developers in providing adequate community facilities towards creating a liveable community. Table 1 shows the number of population and the number of in-patient beds in hospitals.

Table 1 Number of population and number of in-patient beds

\begin{tabular}{|c|c|}
\hline No. of population & No. of in-patient beds \\
\hline$>300,000$ & $>600$ \\
\hline $200,000-300,000$ & $400-600$ \\
\hline $100,000-200,000$ & $200-400$ \\
\hline $50,000-100,000$ & $100-200$ \\
\hline $30,000-50,000$ & $60-100$ \\
\hline$<30,000$ & $<60$ \\
\hline
\end{tabular}

Source: Jabatan Perancangan Bandar dan Desa Semenanjung Malaysia, 2013

In this guideline, the planning provision for clinics is also assigned. The main component of this clinic includes services for maternity, outpatient, dental and pharmacy. Table 2 shows the number of population per clinic.

Table 2 Number of population and clinics' category

\begin{tabular}{|c|c|c|}
\hline Clinics & Health Clinic & Rural Clinic \\
\hline Number of population & $15,000-20,000$ & $1000-4000$ \\
\hline
\end{tabular}

Source: Jabatan Perancangan Bandar dan Desa Semenanjung Malaysia, 2013

Both standards and guidelines are used to measure the allocation of healthcare facilities provided in the study area. The standard is used to measure the ratio in accordance with the global indicator, and the guideline is used to measure the allocation provided is adequate according to the population.

\section{METHODOLOGY}

This study employs a quantitative approach using secondary data on population and healthcare facilities. Melaka is chosen as the study area due to the availability of data on healthcare facilities by districts and population data by mukims, the smallest administrative 
unit available in Malaysia. Both data are not available for other states in Malaysia. Furthermore, Melaka is one of the flood resilient states.

\subsection{The Study Area}

Malacca is in the central region in Malaysia. The area of Malacca is $165,480.94$ hectares. Malacca is divided into three main areas, namely Jasin, Alor Gajah and Malacca Tengah and has 58 mukims. Mukim is the smallest administrative unit in any state in Malaysia.

The main land use of Malacca is agriculture with an area of approximately 118,488.35 hectares $(71.6 \%)$, followed by housing and settlement of $10,019.85$ hectares $(6.05 \%)$, industrial, institutions and businesses $(22.35 \%)$. Malacca has a flat topography drained by rivers flowing from the northeast to the southwest of the Strait of Malacca. However, there are some high-lying areas around the northern states such as Bukit Manis (169m), Hill End (210m), Bukit Punggur $(397 \mathrm{~m})$, and Bukit Batang Malacca (433M). Only about $0.10 \%$ of land is within the category of slope over 25 degrees which is not suitable for development. This statement shows that Malacca has a good potential for development and lacks physical barriers that might hinder development. The population in the state of Malacca is composed of a majority of the Malay community (56.48\%), Chinese $(32.76 \%)$, Indian $(4.19 \%)$, others $(2 \%)$, and non-Malaysian (4.57\%) (Department of Statistics, 2017).

Population data based on age and districts were obtained from the Department of Statistics Malaysia eStatistics portal (Department of Statistics Malaysia, 2017). Melaka Tengah has the highest percentage of the population as compared to the other two districts, Alor Gajah and Jasin. Table 3 shows the details of the population in Melaka according to districts.

Table 3 Population in Melaka according to districts

\begin{tabular}{|l|c|c|}
\hline \multicolumn{1}{|c|}{ District } & Population & Percentage \\
\hline Alor Gajah & 173,712 & 21.99 \\
\hline Jasin & 131,539 & 16.64 \\
\hline Melaka Tengah & 484,885 & 61.37 \\
\hline Total population & 790,136 & 100 \\
\hline
\end{tabular}

Regarding the land use in the three regions, the Malacca Tengah district has an area of 29,874.01 hectares and 602.867 inhabitants. Malacca Tengah is the leader towards achieving the status of city network state and main development corridors' in Malacca. Malacca Tengah also serves as a centre for tourism, education, administration and employment.

Source: Department of Statistics Malaysia, 2017

Data on health care facilities was obtained from Malaysia Government portal, Malaysia Administrative Modernisation and Management Planning Unit (MAMPU, 2017). Table 4 shows the number of health facilities according to types at the district level. The types of health facilities available in Melaka include hospital, community polyclinic, 1Malaysia clinic, rural clinic, private clinic, dental clinic, private pharmacy and health office.

Table 4 Distribution of health care facilities in Melaka according to types and districts

\begin{tabular}{|c|c|c|c|c|c|c|c|c|c|}
\hline District & Hospital & $\begin{array}{c}\text { Health } \\
\text { Office }\end{array}$ & $\begin{array}{c}\text { Community } \\
\text { Polyclinic }\end{array}$ & $\begin{array}{c}\text { Malaysia } \\
\text { Clinic }\end{array}$ & $\begin{array}{l}\text { Rural } \\
\text { Clinic }\end{array}$ & $\begin{array}{c}\text { Private } \\
\text { Clinic }\end{array}$ & $\begin{array}{c}\text { Dental } \\
\text { Clinic }\end{array}$ & $\begin{array}{c}\text { Private } \\
\text { Pharmacy }\end{array}$ & Total \\
\hline $\begin{array}{l}\text { Alor } \\
\text { Gajah }\end{array}$ & 1 & 1 & 9 & 6 & 25 & 29 & 14 & 8 & 93 \\
\hline Jasin & 1 & 1 & 9 & 4 & 20 & 16 & 9 & 6 & 66 \\
\hline $\begin{array}{l}\text { Melaka } \\
\text { Tengah }\end{array}$ & 6 & 1 & 11 & 8 & 14 & 225 & 44 & 65 & 374 \\
\hline Total & 8 & 3 & 29 & 18 & 59 & 270 & 67 & 79 & 533 \\
\hline
\end{tabular}

In Melaka there are three government hospitals with one for each district and four private hospitals will all of them located in Melaka Tengah. The total number of beds for the three government hospitals are 1245 excluding Military Hospital as it is not meant to treat the main population (Ministry of Health Malaysia, 2017) and 1016 for the four private hospitals (Lee, 2016; Oriental Melaka Straits Medical Centre, 2017). Melaka offers private hospitals as its Health Tourism products. Thus, hospitals beds in private hospital are not included in the 
Table 5 Number of hospital beds according to hospitals and districts

\begin{tabular}{|l|l|l|l|l|}
\hline \multirow{2}{*}{ District } & Name of hospitals & $\begin{array}{l}\text { Number } \\
\text { of beds }\end{array}$ & $\begin{array}{l}\text { Total no. } \\
\text { of beds }\end{array}$ & $\begin{array}{l}\text { District } \\
\text { Population }\end{array}$ \\
\hline Alor Gajah & Hospital Alor Gajah & 78 & 1245 & 173,712 \\
\hline Jasin & Hospital Jasin & 76 & & 131,539 \\
\hline \multirow{2}{*}{$\begin{array}{l}\text { Melaka } \\
\text { Tengah }\end{array}$} & Hospital Melaka & 1091 & & 484,885 \\
\cline { 2 - 3 } & Military Hospital & 152 & 1379 \\
\cline { 2 - 3 } & Mahkota Medical Centre & 266 & \multirow{3}{*}{1016} & \\
\cline { 2 - 3 } & Pantai Hospital Ayer Keroh & 250 & \\
\cline { 2 - 3 } & Putra Specialist Hospital & 200 & \\
\cline { 2 - 3 } & Oriental Melaka Straits Medical Centre & 300 & & \\
\hline
\end{tabular}

\subsection{Geographic Information Systems Database}

Before analysis, a geographic information systems (GIS) database was developed on Melaka to achieve the objective of this study. The various software was used to produce this database. Quantum GIS is the software used to develop the GIS database and GeoDa is used to analyse the data spatially. Both software is open source software that is available for researchers to utilise.

\subsection{Analysis}

Tobler's first law of geography states "everything is related to everything else, but near things are more related than distant things." (Tobler, 1970). Thus, spatial statistics will be able to explain the significant level of spatial distribution of any feature on earth. There are various tools that can be used to examine spatial distribution. Among others include nearest neighbourhood analysis and Moran's I. Nearest neighbourhood analysis can determine the distribution of health facilities whether they are clustered, dispersed or randomly distributed (Lee and Wong, 2001). However, the value of each feature in relation to its distance with another feature is unknown of its significant level. To achieve this Moran's I is used. Moran's I (Global Moran's I) refers to a measure of spatial autocorrelation that considers both location and values a feature carried simultaneously. However, Moran's I can only measure a single variable at any one time, and this can only be achieved by using Bivariate Moran's I. Bivariate Moran's I allows researchers to determine the relationship between the concentration of population and the placement of health care facilities. This tool will determine whether the provision of health care facilities is by the allocation stated in the guideline.

\section{FINDINGS}

Population in Melaka is highly concentrated in Melaka Tengah. Local Moran's I output gives a high-high cluster of the population in this district. The other two districts, Alor Gajah and Jasin, show no significant pattern. Figure 1 shows the output of Local Moran's I analysis of population distribution in Melaka.

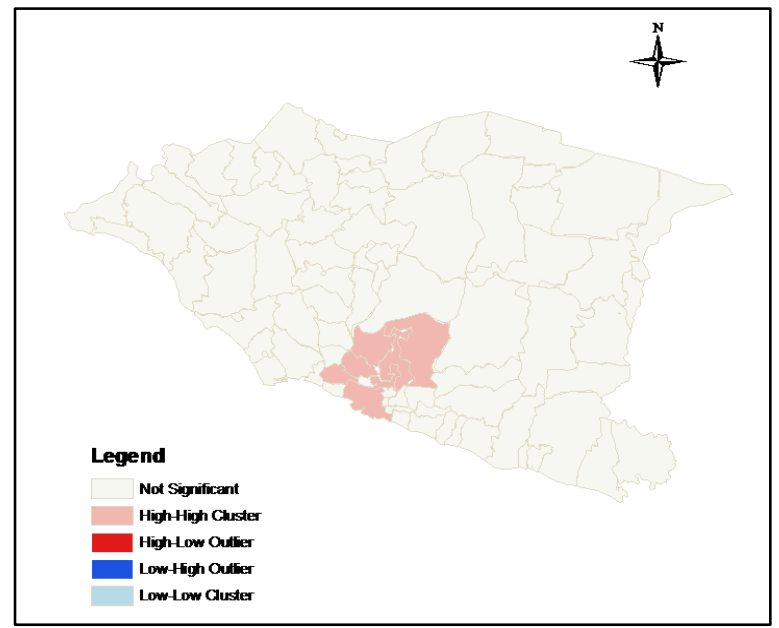

Figure 1 Output of Local Moran's I analysis of population distribution 
Melaka has a high number of private hospital beds due to health tourism promoted by the state government. However, in this study, only public hospital beds are considered. Calculation of ISO37120 standard shows a ratio of a number of hospital beds according to districts. In this calculation, Melaka Tengah has the highest ratio of public hospital beds. Figure 2 shows the distribution of the said ratio.

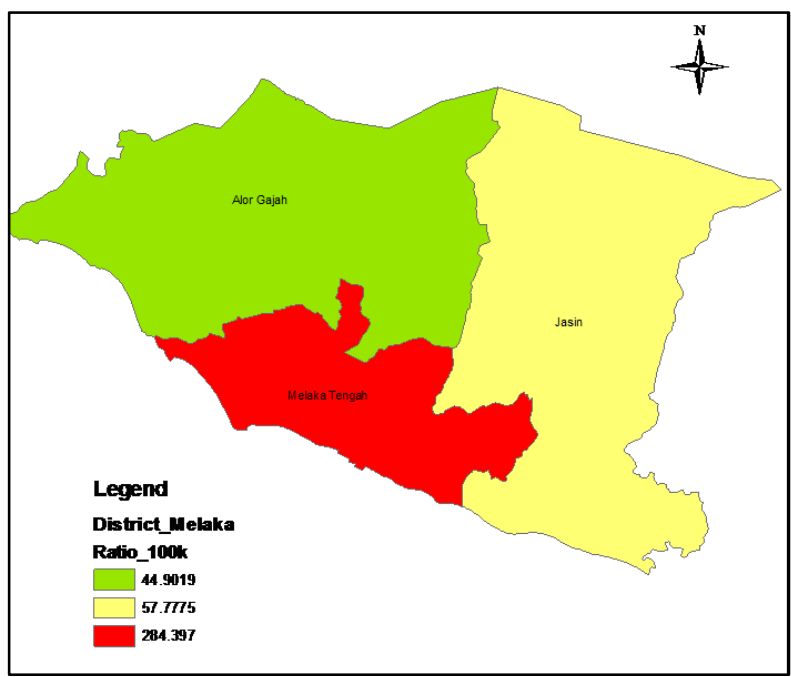

Figure 2 Ratio of public hospital inpatient beds

Bivariate Moran's I analysis of a number of inpatient beds and total population reveals a negative Moran's I value of -0.497079 . This output shows the number of hospital beds is inconsistent with the number of population distribution throughout the state of Melaka. The number of hospital beds is insufficient in all districts in Melaka. Similarly, Bivariate Moran's I analysis with a number of private clinics and pharmacy also score a negative Moran's I values which are -0.499273 and -0.498416 respectively. This output shows the number of private pharmacies is insufficient. Melaka population requires more private pharmacies to be available in their local areas, mukims. In addition, the output of the Bivariate Moran's I analysis shows the number of private clinics is negatively correlated with the number of population. This could be linked to the provision of public clinics. The provision of public clinic shows a positive relationship with a score of Moran's I value of 0.20119 . This result shows the high total number of population is consistent with a higher number of public clinics. Table 6 shows the details of Moran's I score using Bivariate Moran's I analysis.

Table 6 Bivariate Moran's I analysis on total number of population and three other variables

\begin{tabular}{|l|l|}
\hline Variables & Moran's I score \\
\hline Number of public hospital beds and total number of population & -0.497079 \\
\hline Number of public clinics and total number of population & 0.20119 \\
\hline Number of private clinics and total number of population & -0.499273 \\
\hline Number of pharmacy and total number of population & -0.498416 \\
\hline
\end{tabular}

\section{DISCUSSION}

Rough estimation using a guideline may not be able to reflect the actual demand for healthcare facilities. Measurement using guideline may report sufficient allocation of healthcare facilities. However, spatial statistic shows a different indication. The use of Bivariate Moran's I allow spatial analysis to be conducted using two variables. The output of this analysis has shown a significant result that may assist decision makers to make wise decisions. As mentioned by Ujoh \& Kwaghsende (2014) equal distribution may not reflect the actual demand. Thus, spatial statistic, a tool that can show the relationship may provide alternative answers. In this study, the number of hospital beds is insufficient according to population distributed at mukim's level in Melaka. The location of hospitals must be reflected in the concentration of population in a mukim. Thus, placement of hospitals must be relooked into to meet the demand of the population based on mukims. Similarly, the number of private pharmacies must also be increased based on population distribution at mukim level. Placement of these 
pharmacies must meet the demand of the population for any specific mukims. Private clinics, however, are not in demand by the population. This might be due to the high number of public clinics which are accessible at mukim's level. Many studies concentrated on providing a method of determining the best location of healthcare facilities and accessibility. However, this study provides a slightly different research focus in examining the allocation and location of healthcare facilities based on the spatial analysis.

\section{CONCLUSION}

Examining provision of healthcare facilities should be carried out using multiple methods of measurement. Guideline alone may not be able to handle rapid population growth, accessibility, and quality of services. Location of healthcare facilities plays a major role in meeting the demand of the population at mukim's level. The population of any state is not equally distributed. Therefore, placement of healthcare facilities must consider the distribution of the mukim's population before implementation. Bivariate Moran's I has enabled to prove the inconsistencies of healthcare facilities placement. Thus, policy makers and decision makers need to consider multiple methods of analysis to assist them in making wise decisions.

\section{ACKNOWLEDGEMENT}

Authors wish to thank the University of Malaya for grant no. BKP011/13 and Ms Wan Suzita Wan Ibrahim.

\section{REFERENCES}

Ahmadi-Javid, Amir, Seyedi, Pardis, \& S.Syam, Siddhartha. (2017). A survey of healthcare facility location. Computers \& Operations Research, 79(2017), 223-263.

Chakraborty, Keya \& Sen, Joy. (2011). Utility assessment of human development indicators: case of Kolkata urban agglomeration. Journal of Design and Built Environment. 8(1), 1-9.

Daskin, Mark S., \& Dean, Latoya K. (2004). Location of Health Care Facilities. In M. L. Brandeau, F. Sainfort \& W. P. Pierskalla (Eds.), Operations Research and Health Care: A Handbook of Methods and Applications (pp. 43-76). Boston, MA: Springer US.

Department of Statistics Malaysia. (2017). eStatistics. Retrieved 1 June, 2017, from https://newss.statistics.gov.my/newssportalx/ep/epLogin.seam
Gulliford, Martin C., Jack, Ruth H., Adams, Geoffrey, \& Ukoumunne, Obioha C. (2004). Availability and structure of primary medical care services and population health and health care indicators in England. $B M C$ Health Services Research, 4(1), 12. doi: 10.1186/1472-6963-4-12

Ilesanmi, Adetokunbo \& Mgbemena, Emeka. (2015), Urbanization, housing, homelessness and climate change adaptation in Lagos, Nigeria: Lessons from Asia. Journal of Design and Built Environment, 15(2), 15-28. doi: 10.22452/jdbe.vol15no2.3

ISO. (2014). ISO 37120 Sustainable development of communities Indicators for city services and quality of life. Switserland: ISO Copyright Office.

Jabatan Perancangan Bandar dan Desa Semenanjung Malaysia. (2013). Garis panduan perancangan kemudahan perancangan (Vol. GP004-A, pp. 1-87). Kuala Lumpur: Jabatan Perancangan Bandar dan Desa Semenanjung Malaysia.

Kanuganti, Shalini, Sarkar, Ashoke Kumar, \& Singh, Ajit Pratap. (2016). Evaluation of access to health care in rural areas using enhanced two-step floating catchment area (E2SFCA) method. Journal of Transport Geography, 56, 45-52. doi: http://dx.doi.org/10.1016/j.jtrangeo.2016.08. 011

Langford, M, Higgs, G, \& Fry, R. (2016). Multimodal two-step floating catchment area analysis of primary health care accessibility. Health Place., 38, 70-81.

Lee, Peter Waih. (2016). Private hospitals in Melaka. Retrieved 20 June, 2017, from http://hospital.com.my/directory/Melaka/priv ate/index.htm

Lee, J., \& Wong, D. W. S. (2001). Statistical Analysis with ArcView GIS (Vol. 192). New York: John Wiley \& Sons, Inc.

MAMPU. (2017). Kemudahan kesihatan mengikut daerah. data.gov.my, Data For Citizen's Wellbeing. Retrieved 1 June, 2017, from

http://www.data.gov.my/data/en_US/dataset/ kemudahan-kesihatan-mengikut-daerah2012-2014

Ministry of Health Malaysia. (2017). List of government hospital. Retrieved 20 June, 2017, from http://www.moh.gov.my/english.php/databas e_stores/store_view/3

Oriental Melaka Straits Medical Centre. (2017). Who we are. Retrieved 20 June, 2017, from http://orientalmedical.com.my/about-us/whowe-are/

Oyekale, Abayomi Samuel. (2017). Assessment of primary health care facilities' service 
readiness in Nigeria. BMC Health Services Research, 17(1), 172. doi: 10.1186/s12913017-2112-8

Pantzartzis, Efthimia, Edum-Fotwe, Francis T., \& Price, Andrew D. F. (2017). Sustainable healthcare facilities: Reconciling bed capacity and local needs. International Journal of Sustainable Built Environment, 6(1), 54-68. doi: http://dx.doi.org/10.1016/j.ijsbe.2017.01.003

Polo, Gina, Acosta, C. Mera, Ferreira, Fernando, \& Dias, Ricardo Augusto. (2015). LocationAllocation and Accessibility Models for Improving the Spatial Planning of Public Health Services. PLOS ONE, 10(3), e0119190.

doi: 10.1371/journal.pone.0119190

Radke, John, \& Mu, Lan. (2000). Spatial Decompositions, Modeling and Mapping Service Regions to Predict Access to Social Programs. Geographic Information Sciences, 6(2), 105-112. doi: 10.1080/10824000009480538

Rahman, Shams-ur, \& Smith, David K.. (2000). Use of location-allocation models in health service development planning in developing nations. Eur J Oper Res, 123(3), 437-452.

Song, Peige, Zhu, Yajie, Mao, Xi, Li, Qi, \& An, Lin. (2013). Assessing Spatial Accessibility to Maternity Units in Shenzhen, China. PLOS ONE, 8(7), e70227. doi: 10.1371/journal.pone.0070227

Tobler, W. 1970. A computer movie simulating urban growth in the Detroit region. Economic Geography, 46:234-40.

Ujoh, Fanan, \& Kwaghsende, Felix. (2014). Analysis of the spatial distribution of health facilities in Benue State, Nigeria. Public Health Research, 4(5), 210-218.

Wan, Neng, Zou, Bin, \& Sternberg, Troy. (2012). A three-step floating catchment area method for analyzing spatial access to health services. International Journal of Geographical Information Science, 26(6), 1073-1089. doi: 10.1080/13658816.2011.624987

Zinszer, K, Charland, K, Kigozi, R, Dorsey, G, Kamya, MR, \& Buckeridge, DL. (2014). Determining health-care facility catchment areas in Uganda using data on malaria-related visits. Bull World Health Organ, 92(3), 178186. 